\title{
Dietary phytochemicals and cancer chemoprevention: a review of the clinical evidence
}

\author{
Ritesh Kotecha ${ }^{1}$, Akiyoshi Takami² and J. Luis Espinoza ${ }^{3}$ \\ ${ }^{1}$ Department of Medicine, Beth Israel Deaconess Medical Center, Boston, MA, United States of America \\ ${ }^{2}$ Department of Internal Medicine, Division of Hematology, Aichi Medical University, School of Medicine, Nagakute, Aichi, \\ Japan \\ ${ }^{3}$ Department of Hematology Oncology, Kanazawa University Graduate School of Medical Science, Kanazawa, Japan \\ Correspondence to: J. Luis Espinoza, email: Ivis@staff.kanazawa-U.ac.jp \\ Keywords: cancer chemoprevention, phytochemicals, resveratrol, curcumin, antioxidants \\ Received: December 30, $2015 \quad$ Accepted: May 12, $2016 \quad$ Published: May 24, 2016
}

\section{ABSTRACT}

Cancer chemoprevention involves the use of different natural or biologic agents to inhibit or reverse tumor growth. Epidemiological and pre-clinical data suggest that various natural phytochemicals and dietary compounds possess chemopreventive properties, and in-vitro and animal studies support that these compounds may modulate signaling pathways involved in cell proliferation and apoptosis in transformed cells, enhance the host immune system and sensitize malignant cells to cytotoxic agents. Despite promising results from experimental studies, only a limited number of these compounds have been tested in clinical trials and have shown variable results. In this review, we summarize the data regarding select phytochemicals including curcumin, resveratrol, lycopene, folates and tea polyphenols with emphasis on the clinical evidence supporting the efficacy of these compounds in high-risk populations.

\section{INTRODUCTION}

Despite modern advances in medical therapeutics worldwide, cancer continues to account for more than fourteen million new cases and roughly eight million deaths each year [1]. Increases in global cancer incidence over the past several years have led to campaigns focused specifically on disease prevention, and detectable declines in global cancer incidence have been achieved through efforts such as tobacco cessation movements and vaccinations [1]. Epidemiological studies have also uncovered that diet and exercise may significantly impact the prevalence of specific types of cancers, renewing interest in dietary phytochemical research [2-4].

Phytochemicals constitute a heterogeneous set of bioactive compounds classified by chemical structure and include polyphenols, alkaloids, carotenoids, and nitrogen compounds [5]. These compounds are naturally found in fruits, vegetables, grains and other plant products and are often responsible for distinct plant characteristics such as color pigmentation and smell. Moreover, many are integral for host protection against viruses, parasites and other externally damaging agents. Initial studies have revealed that these compounds are able to affect cell proliferation and cell cycle regulation, and usually participate in multiple signaling pathways which are often disrupted in tumor initiation, proliferation and propagation [5-9].

Although prior observations have guided multiple successful pre-clinical studies, only a limited number of clinical trials have been able to fully expose the distinct impact each dietary phytochemical may have on cancer prevention [8]. Many of these failures have been attributed to the variable bioavailability and distribution of compounds, optimal mixtures of several phytochemicals, and the appreciable risk reduction that may take several years to detect in large population studies. As global cancer incidence continues to rise, understanding the impact of these dietary modifications may fuel simple and inexpensive ways to improve health worldwide. Here, we review the history and latest clinical findings on select dietary compounds including curcumin, resveratrol, tea polyphenols, lycopene and antioxidants.

\section{AN OVERVIEW OF CARCINOGENESIS}

Carcinogenesis is a multistep process characterized by a progression of distinct molecular changes that ultimately reprogram and transform a cell to undergo uncontrolled cellular division [10]. During the last fifty years, research has uncovered innumerable 
critical molecular players and targeted pathways, and highlighted the underlying balance of aberrant activation of proto-oncogenes and inactivation of tumor suppressor genes. With each disruption, cells undergo changes fundamentally represented by tumor initiation, promotion and progression [11, 12]

Tumor initiation is a rapid and irreversible process that starts with an exposure to a carcinogenic agent, followed by its distribution and transportation to tissues causing non-lethal mutations in cellular DNA. These "initiated cells" begin to accumulate additional irreversible genetic changes which persist with each new cycle of proliferation [12]. Functionally, initiated cells are more immune to inhibitory signals mediated by cell differentiation inducers and negative growth regulators $[13,14]$.

Tumor promotion involves the selective clonal expansion and proliferation of initiated cells allowing for additional mutations to accumulate. In contrast to initiation, tumor promotion is a relatively lengthy and reversible process in which actively proliferating preneoplastic cells begin to divide and propagate. Tumor progression, the final stage of neoplastic transformation, occurs after these mutations result in an invasive cellular phenotype with metastatic potential $[12,15]$.

Advances in our understandings of tumor development show that each step is composed of highly variable and intricate systems. For instance, epigenetic changes of tumor suppressor genes through DNA methylation in pre-neoplastic tissues may result in accelerated carcinogenesis [16, 17]. The dynamic regulation of proteins involved in cellular apoptosis by micro-RNAs may significantly impact both tumor promotion and progression [18]. Finally, more recent evidence has highlighted the critical role of the tumor microenvironment on the survival and mutation of preneoplastic cells [14].

Cancer chemoprevention centers on the identification of agents that specifically impact early stages of cellular transformation [19, 20]. Naturally occurring phytochemicals have been found to have a wide range of cellular effects (Figure 1). For instance, phytochemicals may prevent carcinogens from reaching targeted sites and support detoxification of highly reactive molecules

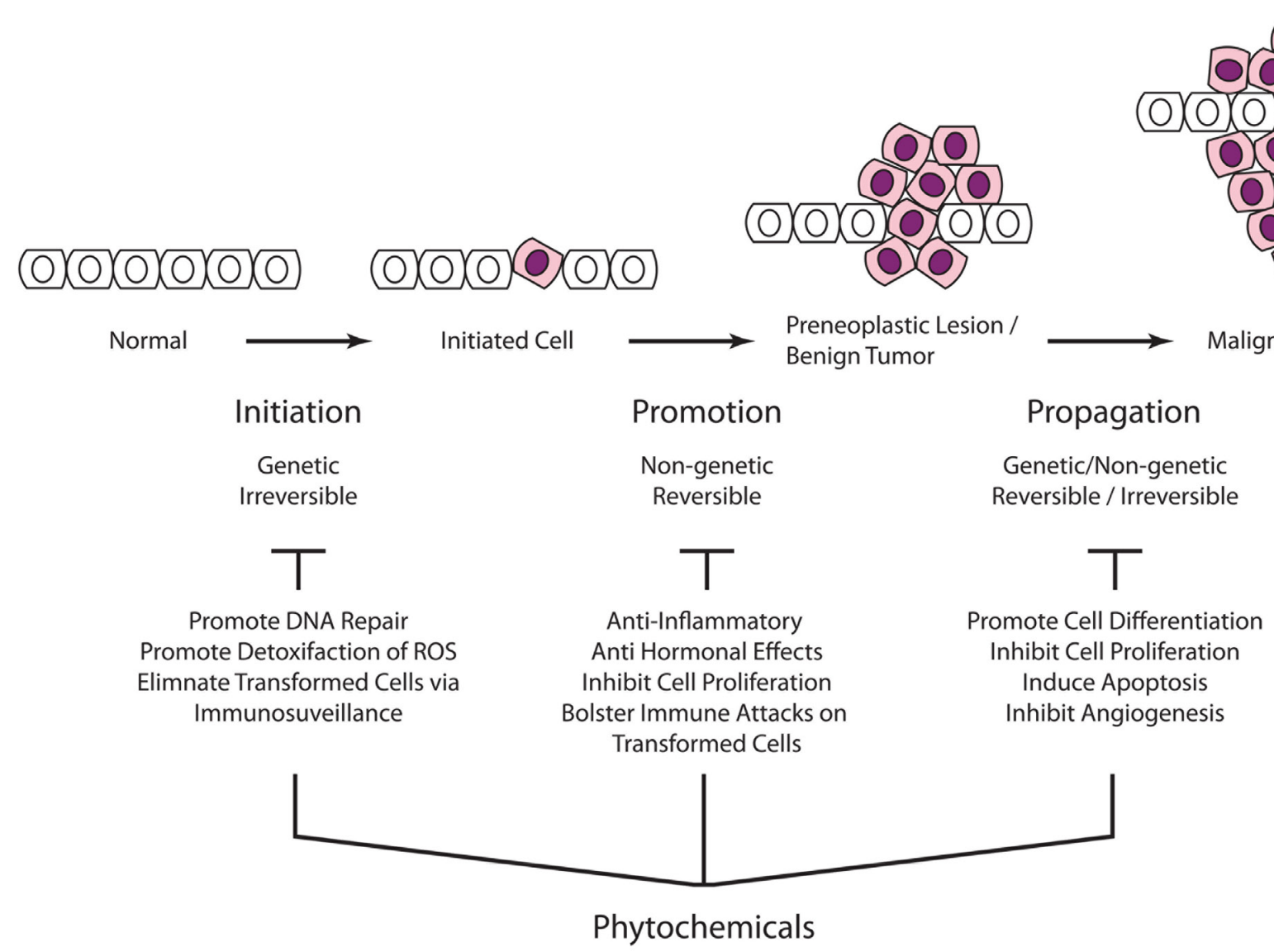

Figure 1: Carcinogenesis is a multistep process that ultimately reprogram a normal cell into a cancer cell. Phytochemicals may exert their chemopreventive effects by blocking key events of tumor initiation and promotion thus reversing the premalignant stage. These agents may also prevent tumorigenesis by inhibiting or retarding tumor progression or by promoting cell differentiation. 
[21]. Select phytochemicals also enhance innate immune surveillance and improve the elimination of transformed cells [22]. Finally, phytochemicals have several impacts on intrinsic DNA repair mechanisms and may influence tumor suppressors and inhibit cellular proliferation pathways [19].

\section{CURCUMIN}

Curcumin, or turmeric (bis- $\alpha, \beta$-unsaturated $\beta$ diketone), is a polyphenol derived from the roots of the perennial Curcuma Longa plant, and is a gold-colored spice widely used in Indian cooking, textile dyes, and in traditional Ayurvedic medicine [23]. In recent decades, in vitro models have shown that curcumin inhibits the growth of a variety of cell lines by inducing cell cycle arrest and apoptosis, most importantly through pleiotropic modulation on several distinct cancer targets including nuclear factor kappa B (NF-kB), cyclooxygenase-2 (COX-2), tumor necrosis factor alpha (TNF- $\alpha)$, STAT-3 and cyclin D1 [23-26]. Building upon pre-clinical work, several phase I clinical trials have confirmed both the safety and pharmacokinetics of curcumin in patients with doses escalated up to eight grams per day, and these trials have shown measurable biological effects in patients with a variety of malignancies including pancreatic cancer, multiple myeloma and advanced colorectal cancer refractory to standard chemotherapy [27-30].

Curcumin is preferentially distributed into the colonic mucosa compared with other tissues, leading many initial clinical studies to focus on identifying whether this compound may play a role in colorectal cancer models [24]. This hypothesis was tested in patients with familial adenomatous polyposis (FAP), an inherited condition that leads to unregulated development of innumerable precancerous adenomatous growths throughout the colon with eventual development of colorectal cancer at a young age. In one study, patients were given a combination of curcumin and quercetin $(400 / 20 \mathrm{mg})$, a common flavonoid compound found in several supplements and foods. Compared to baseline colonoscopies performed prior to initiation of treatment, all five patients tested were found to have a decreased number of polyps and reduced polyp size after six months of treatment without other laboratory abnormalities and minimal adverse effects [31]. Although this study was limited and used a combination of both curcumin and quercetin, it raised awareness for future research testing the therapeutic potential of curcumin in pre-cancerous models [31].

Other small studies have similarly shown that high doses of curcumin may have a preventive effect in pre-cancerous models. In an open-label phase II clinical study, Carroll and colleagues investigated the effects of daily curcumin on aberrant crypt foci (ACF). ACF are proposed to be the earliest histologic sign for colonic neoplastic lesions and are composed of abnormal crypt zones with high levels of prostaglandin-E2 (PGE-2) and 5-eleicosatetraenoic acid (5-HETE). Participants were randomized to either two or four grams of daily curcumin, and underwent colonoscopies prior to and after thirty days of treatment [32]. Although this study found no significant reduction in PGE-2 or 5-HETE serum levels, patients taking four grams of daily curcumin were found to have a $40 \%$ reduction in the number of ACF lesions compared with those taking two grams of curcumin. Moreover, a recent phase I clinical trial highlighted that these clinical effects may be applicable in other high-risk precursor lesions including oral leukoplakia, intestinal metaplasia of the stomach and cervical intraepithelial neoplasia, as some treated patients were found to have histological improvement of precursor lesions compared to baseline after three months of high dose curcumin supplementation [33].

To extend the potential clinical effect of curcumin in these high-risk populations, current research has shifted focus to improving bioavailability to overcome both the variability of absorption and rapid compound metabolism. Several attempts combining curcumin with glucuronidation inhibitors such as piperine to inhibit hepatic and intestinal metabolism have shown promising results [34]. Other efforts have focused on altering compound delivery by liposomal or phospholipid complexing, as well as utilizing curcumin analogues and nanoparticles [35, 36]. Recently, a phase I dose-escalation study showed that participants receiving single dose liposomal curcumin $\left(10-400 \mathrm{mg} / \mathrm{m}^{2}\right)$ had a dose dependent increase in both the plasma concentration of curcumin and its active metabolite tetrahydrocurcumin (THC) without clinical side effects. Red blood cell morphology changes were seen at curcumin doses greater than $120 \mathrm{mg} / \mathrm{m}^{2}$, possibly indicating a dose limiting sign of toxicity [37]. Additionally, liquid micellar curcumin formulations have shown to have significant bioavailability without increased toxicities. In a recent crossover study, patients given liquid micellar formulations compared to curcuminoid powder or micronized powder had a 185 fold increase in bioavailability within twenty four hours, with a twofold increase in women compared with men in absorptive efficacy [38].

\section{RESVERATROL}

Resveratrol is a phytoalexin found in many fruits and plants including red wine, grapes, berries and peanuts [39]. The roots of the polygonum cuspidatum, or Japanese knotweed, contains the highest naturally occurring levels of resveratrol and has been used in traditional Japanese and Chinese medicinal treatments for dermatitis, bacterial infections and inflammation. Plants produce resveratrol in response usually to mechanical injuries, ultraviolet radiation and as a defense for viral and fungal infections $[39,40]$. Resveratrol has become the most common 
phytoalexin currently studied in modern healthcare because of the highly publicized "French Paradox", an observation that there is a relatively low incidence of cardiovascular disease in France despite a particularly rich saturated-fat diet from the high consumption of red wine [41].

Early studies identified that resveratrol has anticancer effects against several different tumor type and affects multiple stages of tumor initiation and proliferation. Specifically, resveratrol can induce cancer cell apoptosis by interfering with multiple signaling pathways activated in transformed cells [40-45]. Clinical trials have also defined the safety, pharmacokinetics and metabolism as both a single synthetic agent and constituent of food at variable doses [46]. These studies also showed that adverse effects including diarrhea, nausea and abdominal pain occur in those taking more than one gram of resveratrol daily, which has now become a standard dose limit in subsequent clinical work [46].

Resveratrol supplementation and its potential effects in healthy subjects have been recently tested in clinical trials. Firstly, one study investigated the effects of resveratrol at variable high doses $(0.5,1,2.5$ and 5 grams / day for 29 days; $n=10-12$ / dose) on circulating levels of insulin-like growth factor (IGF-1) and IGF-binding protein 3 (IGFBP-3) [47], two markers often associated with increased tumor formation and subsequent metastasis [48]. Unexpectedly, these doses were found to be safe and higher doses of five grams daily were associated with mild gastrointestinal adverse effects. Subjects given 2.5 grams daily of resveratrol showed significantly reduced levels of circulating IGF-1 and IGFBP-3 plasma levels [47], suggesting possible chemopreventive potential. Future analyses using these surrogates will need to be interpreted with caution as concentrations of IGF-1 and IGFBP-3 vary in different cancer models and are strongly influenced by other dietary compounds including citrus fruits and Vitamin C [49].

Chow and colleagues set out to investigate whether resveratrol would have an effect on drug metabolism and enzymes associated with carcinogenesis. In their study, one gram of resveratrol daily for four weeks was found to have significant inhibitory effects on plasma cytochrome P450 enzymes, including CYP3A4, 2D6, and 2C9, and enhanced CYP1A2 compared with baseline measurements in healthy volunteers [50]. These modulatory effects on enzymatic systems used in detoxification and carcinogen activation may account for some chemopreventive effects, and also importantly may alter metabolism of other agents. As many chemotherapeutic and other medications are metabolized through the cytochrome system, this study critically raises safety concerns for co-administration with other pharmaceutical agents.

The effect of resveratrol has also been heavily studied in patients with breast cancer. In a case-control study, Levi and colleagues showed that women with high total intake of resveratrol had a lower risk of breast cancer compared with women with a low level of ingestion (OR: 0.39) [51]. More recently, a randomized, double-blind placebo trial showed that in women at an increased risk for development of breast cancer, twice daily resveratrol dosing for twelve weeks was associated with a decrease in methylation of four cancer related genes on mammary tissue biopsies post-treatment. This work highlights the direct in-vitro anti-proliferative effect and mechanism in tissue specimens after treatment [52]. Other pre-clinical and clinical studies have proposed that resveratrol may also modulate hormonal metabolism and effects used in breast cancer and prostate cancer. In a randomized placebo controlled trial, Kjaer and colleagues showed that although resveratrol intake was not associated with prostate size or reduction in prostate serum antigen levels, it was associated with lower levels of androgen precursors including androstenolone (DHEA) and therefore may have a relevant effect in benign prostatic hyperplasia and cancer growth [53]. These findings are consistent with previously pre-clinical work reporting that resveratrol suppresses prostate cancer growth in rat models, an effect largely mediated through down-regulation of androgen receptor expression and suppression of androgen responsive glandular kallikrein, an orthologue of the human prostate specific antigen (PSA) [54].

The potential therapeutic effect of resveratrol may also be through promoting immunosurveillance through the innate immune system thereby enhancing elimination of spontaneous tumor cells prior to proliferation. Natural killer (NK) cells are the primary effector lymphocytes of this system and are able to importantly recognize transformed or infected cells without prior education by antigen process cells. This allows NK cells to effectively eliminate rapidly progressing tumor cells at a much more rapid rate compared with $\mathrm{T}$ lymphocytes, which require antigen recognition and education prior to activation [55]. NKG2D, an antigen receptor expressed by cytotoxic lymphocytes including NK cells, CD8 and $\gamma \delta$ T cells, appears to play a significant role in tumor surveillance as these cells utilize the NKG2D receptor to identify specific surface ligands expressed on transformed cells for cytotoxicity [56].

To delineate the potential role of resveratrol in the innate immune system, a clinical trial focused on detecting differences in immune system profiles was performed in healthy subjects given one gram of resveratrol daily for two weeks. Administration of this compound was found to correlate with enhanced expression of NKG2D receptor on circulating peripheral blood NK cells [57]. Since preclinical studies have confirmed that resveratrol can induce the expression of NKG2D ligands in transformed cells and thus render these cells more susceptible to NK cell lysis via NKG2D cytotoxic pathways [22], this study suggested that resveratrol may modulate this axis to allow for increased tumor surveillance by the innate immune 
system [22].

Pharmacokinetic evidence indicate that resveratrol has poor bioavailability due to its rapid and extensive liver metabolism which severely impairs its therapeutic effects $[58,59]$. Several approaches, with variable results, have been attempted to overcome this problem [60], including combining resveratrol with glucuronidation inhibitors such as piperine [59], developing resveratrol nanoparticles [61, $62]$, and utilizing novel drug delivery systems to protect and stabilize resveratrol to enhance its bioavailability [63, 64]. Further studies in humans are needed to determine the optimal delivery system to achieve clinically relevant levels of resveratrol.

\section{TEA POLYPHENOLS}

Camellia sinensis, or tea, is one of the most ancient and popular beverages consumed across the world. Although the specific composition varies widely, tea is usually composed of a combination of polyphenols, alkaloids, minerals, and other volatile organic compounds [65]. Further, there is a very high proportion of catechin polyphenols such as Epigallocatechin-3-gallate (EGCG) and Epicatechin-3-gallate (ECG). Interestingly, green tea contains much higher concentration of these specific catechins compared with other black teas [66]. Catechin polyphenols, particularly EGCG and EBCG have robust antioxidant activity and are thought to exert their role as antioxidants by preventing specific DNA damage by reactive oxygen species, thereby preventing tumor mutagenesis of normal cells $[65,66]$. In pre-clinical studies, tea polyphenols have been shown to directly inhibit tumor cell growth by inducing apoptosis through multiple pathways linked in cancer development [67]. Tea polyphenols have also been implicated in multiple carcinogenesis pathways including inhibiting angiogenesis modulating the immune system, and activating enzyme systems involved in cellular detoxification through the glutathione S-transferase and quinone reductase pathways [68].

Multiple studies have shown overall conflicting data regarding the potential cancer risk reductive properties of green tea in various populations [69]. This inconsistency in results may be in part because multiple types of teas are often used in trials and have variable tea preparations, unknown concentrations of different types of antioxidants, and the bioavailability of many of these compounds after ingestion is different across populations. Furthermore, many of these studies are often confounded by other ingestions that may overall lead to the development of cancers including tobacco and alcohol use and it is difficult to distinguish these confounding variables [70].

To date, there have been several clinical trials that have set out to identify the potential clinical role these tea polyphenols may have in cancer prevention. Two randomized clinical trials evaluated the effects of tea extracts on premalignant oral lesions called leukoplakia. In a double blinded interventional trial, subjects were given either three grams of mixed tea product, both orally and topically, or placebo. After six months of treatment, $38 \%$ of patients in the treatment group had partial regression of their oral lesions compared to $10 \%$ in the placebo group. Furthermore, progression in the lesions size was lower compared to the treatment group, $3 \%$ vs. $7 \%$ [71]. In addition, a second trial repeated this with premalignant oral lesions randomly assigned to receive either $500 \mathrm{mg}, 700 \mathrm{mg}$ or $1000 \mathrm{mg} / \mathrm{m}^{2}$ of tea extract compared to placebo three times daily for twelve weeks. Although not statistically significant, those in the tea extract arm were found to have an overall better clinical response and improvement in lesion histology [53].

Other studies have utilized the impact of treatments on specific biomarkers as potential signs for cancer risk reduction. Urinary levels of 8-hydroxydeoxygnaunosine (8-OHdG), a biomarker of oxidative DNA damage has been shown to be elevated in patients with lung, liver, kidney, brain, stomach and ovarian cancers [72]. Recently, randomized controlled clinical trials showed that green tea significantly decreased urinary levels of 8-OHdG in adult heavy smokers $[73,74]$. These findings were confirmed in another trial, as high risk individuals for liver cancer due to hepatic infections or aflatoxin was given green tea supplements of 500 or $1000 \mathrm{mg}$ daily for 3 months compared with placebo showed significantly lower 8-OHdG levels [75]. In contrast, levels of pepsinogen, a marker of gastric atrophy that has been shown to indicate increased risk for stomach cancer, were not affected by treatments with tea polyphenols for one year of treatment [76]. Therefore, although tea polyphenols have shown to influence certain biomarkers involved in cancer propagation, the clinical risk reductive effect of polyphenols still remains unclear. This conclusion was further validated after Zheng and colleagues in a study of prostate cancer in the Asian population [59].

\section{ANTIOXIDANTS}

Reactive oxygen species (ROS), or free radicals like superoxide $(\mathrm{O} 2-)$, hydrogen peroxide $(\mathrm{H} 2 \mathrm{O} 2)$ and peroxynitrite $(\mathrm{OONO}-)$ are produced during aerobic cellular metabolism. In normal cells, low level concentrations of these compounds are required for signal transduction, however excessive levels of ROS can induce damage to all cellular components, including proteins, lipids, carbohydrates, and nucleic acids [77]. Oxidative stress reflects an imbalance between production of ROS and an adequate antioxidant defense. Due to the unchecked dramatic cell proliferation of cancer cells, higher amounts of ROS are produced with increased proliferation [77, 78].

Antioxidants are known as free radical scavengers since they are able to interact with and neutralize free radical species. Endogenous antioxidants naturally 
produced in the body help neutralize these ROS, and external sources of antioxidants are also supplanted from fruits, vegetables and grains [11]. Lycopene, beta carotene, Vitamins A, C, E, selenium and other dietary antioxidants have been broadly studied in humans for preventing inflammation, cancer and other stress related disease. Pre-clinical studies have shown that antioxidants are capable of preventing cellular damage induced by free ROS, suggesting that cancer development may be slowed in the setting of increased levels of dietary exogenous or endogenous antioxidant supplements [79].

Epidemiological studies have shown mixed results regarding antioxidant supplementation and effects on primary cancer prevention [80]. One of the most prominent first trials was the Carotene and Retinol Efficacy (CARET) which examined the effects of daily supplementation with beta carotene and retinol on the incidence of lung cancer, and other cancers and death from incidence, and showed that both beta carotene (15 $\mathrm{mg}$ ) and retinol (25,000 IU) daily supplementation was associated with increased lung cancer and increased allcause mortality [81]. These adverse effects persisted up to six years after supplementation ended as reported in an updated study with the caveat that the higher risk of lung cancer and all-cause mortality were no longer statistically significant [82]. Similarly, the Linxian trial showed that a combination of $15 \mathrm{mg}$ of beta carotene, alpha tocopherol $30 \mathrm{mg}$, and selenium $50 \mu \mathrm{g}$ daily for five years initially showed a lower mortality risk from gastric cancer but not esophageal cancer. The study also concluded that polyphenols did not affect the risk of developing either gastric or esophageal cancer [83]. A new report ten years later analyzing those who took this antioxidant supplementation compared with placebo failed to show this persistent reduced risk of mortality [84].

Trials that have failed to show clinical significance of antioxidant therapy in cancer prevention have been performed in a variety of other models. Beta-carotene and/or alpha-tocopherol has failed to show an effect on the incidence of lung cancer and other cancers including urothelial, pancreatic, colorectal, and digestive tract cancers [85-88]. Expanding this to other supplements has also yielded mixed results. Clinical studies of alpha tocopherol (400 IU) and/or Vitamin C (500 mg) in combination versus placebo did not reduce the incidence of prostate cancer or other cancers including lymphoma, leukemia, melanoma, lung, bladder pancreas, or colorectal cancers in male U.S physicians older than 50 years of age for a median of 7.6 years of follow-up [89]. The authors also concluded post-trial that after a mean of 10.3 years of follow-up, alpha-tocopherol and Vitamin C supplementation had no immediate or long-term detectable effects on the risk of total or site-specific cancers [90].

There have been several studies that have highlighted that although anti-oxidants may have clinical roles in cancer pathways, there is still much to be understood about combinations to yield positive results. The "Supplementation en Vitamins et Meraux Antioxidants" (SU.VI.MAX) trial utilized a combination of several antioxidants and minerals including Vitamin C (120 mg), Vitamin E (30 mg), beta-carotene (6 mg), selenium $(100 \mu \mathrm{g})$ and Zinc $(20 \mathrm{mg})$ showed no global effect on cancer, cardiovascular disease, or all-cause mortality during median 7.5 years of treatment. However, specific analyses revealed an increase in skin cancer incidence among women only, leading to an overall lower cancer incidence and mortality among men only [91]. An updated study of these patients revealed that the effect disappeared within 5 years of ending supplementation [92].

A similar study showed that a combination of selenium $(200 \mu \mathrm{g})$ and Vitamin E (400 IU) daily for a median of 5.5 years did not reduce the incidence of prostate or other cancers in men older than 50 [93]. However, updated findings from this study showed that after a mean of seven years, the incidence of prostate cancer was $17 \%$ higher among men taking Vitamin $\mathrm{E}$ alone compared with men taking placebo [94]. This adverse effect was not observed in the selenium alone or Vitamin E and selenium groups [93]. Selenium supplementation has recently been shown to have no clinical benefit in men with low selenium baseline levels, and instead increases the risk for prostate cancer in those who have high baseline selenium levels [95]. Moreover, Vitamin E supplementation also was found to have an increased risk of cancer in those who have low selenium status, and therefore authors have concluded that men should avoid selenium or Vitamin E supplementing at higher than recommended doses [96].

One possible reason for the lack of positive clinical results in antioxidant chemo preventive therapy can be that many antioxidants are consumed in a complex mixture of antioxidants, vitamins, and minerals. Differences in chemical composition of naturally occurring antioxidants in food compared with those purified into supplements may contribute to these effects. For instance, Vitamin $\mathrm{E}$, which can be found in eight different chemical forms in nature and usually found in supplements as alphatocopherol [97]. Additionally, although many of these studies have been performed over long time periods, the executive effect of antioxidants may require longer longitudinal studies to identify small effects, and may only apply to individuals who already have increased oxidative ROS species at baseline. Therefore, further studies that identify balanced composites of vitamins, antioxidants and minerals to create a balanced combination and applying this to individuals with measurable increased oxidative stress may help yield more encouraging results.

\section{FOLATE AND FOLIC ACID}

Folate, also known as folacin, pteroylglutamic acid or vitamin B9, is a water-solute B-vitamin that is a cofactor 
in carbon transfer reactions essential in DNA synthesis, repair and methylation [98]. Since humans are incapable of synthesizing folates de novo, many supplements and foods are fortified with a synthetic form called folic acid. Important dietary sources include green leafy vegetables, asparagus, and broccoli [99].

Preclinical studies have suggested that folate may have anti-cancer properties because of its role in DNA repair and its role in modulating $\mathrm{S}$-adenosylmethionine, a universal methyl donor group for DNA methylation reactions. Therefore, several large scale cross sectional studies have shown that dietary folate intake may be associated with a lower risk of several cancers including lung, breast, pancreatic, esophagus, stomach and colorectal cancer $[100,101]$. Results from large prospective studies have shown that there is a near $25 \%$ risk reduction in the risk of colorectal cancer in those with high folate intake compared with low intake. Recently, a meta-analysis (16 prospective and 26 case control studies) revealed that women with higher daily dietary folate intake had a significant reduction in breast cancer risk compared with those with lower folate intake. Interestingly, despite this effect, there was no significant association between circulating folate levels and breast cancer risk [102].

Building upon epidemiologic population data, several clinical trials have been conducted to assess whether folic acid supplementation is associated directly with appreciable cancer reduction. In a small placebo controlled trial in which 94 patients with colorectal adenomas were assigned to receive either a daily $5 \mathrm{mg}$ dose of folic acid or placebo, folic acid supplementation was associated with a 3-fold decrease in colonic polyp recurrence at three year follow-up [103], however larger trials and meta-analyses have failed to show a reduction in colorectal adenoma risk [104, 105]. The unexpected results from these studies have raised the possibility that folic acid supplementation may actually increase the risk of colorectal neoplasia [106]. For instance, a recent meta-analysis from Wien and colleagues evaluated twelve randomized controlled trials and seven observational studies and concluded that there was no difference in cancer incidence between controls and participants taking folic acid supplements in observational studies. However, meta-analyses of the randomized controlled trials showed a modest increase in frequency of overall cancer in the folic acid groups with a relative risk of 1.07 (95\% CI: 1.00-1.14). Notably, further examination showed that prostate cancer was the only cancer type with a significant increase in risk associated with folic acid supplementation [107].

\section{LYCOPENE}

Lycopene is a naturally occurring carotenoid found in many fruits and vegetables, with particularly high concentration in tomatoes and tomato-based products
[108]. Experimental studies have shown that lycopene lowers intracellular generation of reactive oxygen species (ROS) by possibly augmenting proteins involved in antioxidant reactions including superoxide dismutase-1 (SOD-1) and glutathione-S-transferase-omega-1. Lycopene may also reduce oxidative stress by downregulating expression of ROS generating proteins such as ERO-1 like protein- $\alpha$ and CLIC-1 [109]. Furthermore, lycopene has also been shown to inhibit cell proliferation, induce apoptosis, and in prostate cancer models, has shown to attenuate the metastatic capacity of cancer cells [109, 110].

Consistent with prior experimental data, epidemiological and observational studies have linked increased consumption of lycopene-rich food with lower prostate cancer risks [111-113]. In a meta-analysis of twenty-one observational studies, both moderate and high lycopene rich diets were associated with lower prostate cancer incidence, $6 \%$ and $11 \%$ respectively. Though this study concluded that the trend was not statistically significant, it highlighted that single interventional randomized trials are required to assess the true clinical effect [114]. A recent meta-analysis of eight randomized clinical trials showed a minor, insignificant decrease in the incidence of benign prostatic hyperplasia and prostate cancer patients compared to controls [112].

Interestingly, a recent double blinded randomized controlled trial focused on patients with high-grade prostatic intraepithelial neoplasia and/or atypical small acinar proliferation. Patients in this trial were given a high dose supplement containing lycopene, selenium and green tea catechin for six months, and showed that there were no significant difference in PSA levels between the two groups, but there was a higher incidence of prostate cancer at re-biopsy. Further, micro-RNA profiling of the biopsy samples had higher levels of prostate cancer specific progression biomarkers, thereby concluding that high doses of these types of supplements should be avoided in patients with prostatic intraepithelial neoplasia [115]. Other clinical studies have shown similar results that lycopene correlates with a significant decrease in PSA levels, however the significance has not been mirrored in clinical outcomes $[112,113]$. With the limited number and heterogeneity of existing studies, there is insufficient evidence to support or refute the use of lycopene in precancer models.

\section{ADDRESSING CHALLENGES FOR FUTURE CLINICAL TRIALS}

Despite the potential public health benefit and scientific importance, cancer chemoprevention has not been widely adopted in clinical practice. The poor translational of many pre-clinical findings into clinically effective cancer preventative therapies may be in part due to limitations of current clinical trial design, and failure 
to identify those specifically at high risk. Changing the way trials are performed in the future may help uncover potential health benefits in significant ways.

Cancer incidence is commonly used as a primary endpoint in many clinical trials to evaluate the impact of an intervention on cancer prevention. As described earlier, the latency from progression of malignant cells transformations to detectable cancer lesions may sometimes require decades of patient data. Many studies may lack the financial budget or research infrastructure to overcome this practical obstacle, and adherence to a prescribed regimen may continue to decline as trials progress [7, 116, 117]. Utilizing high-risk premalignant lesions including adenomas, colonic ACFs, mammographic breast densities, or intraepithelial neoplasia in the head and neck as surrogates may also influence the predictive accuracy of therapies as many lesions have variable frequencies for transformation and spontaneous regression [118, 119].

Utilizing cancer chemical biomarkers may represent a better way to assess responses in patients taking these dietary phytochemicals. In a chemoprevention setting, an optimal cancer biomarkers should be accurately measurable and occur prior to cancer development and correlate with malignant transformation and progression [117]. High-throughput screening methods utilizing functional genomic, transcriptomics, proteomics and metabolomics studies have identified many new potential biomarkers of early carcinogenesis. For instance, genomic profiling of airway epithelial samples from smokers at high risk for lung cancer have identified a genomic signature compatible with the phosphatidylinositol 3-kinase (PI3K) pathway activation in cytologically normal bronchial airways of smokers with lung cancer and dysplastic lesions, suggesting that PI3K activation in the proximal airway is a measurable, reversible step preceding development of lung cancer [120]. Genomic studies have also identified miRNA and target gene dysregulation in other precancerous lesions, supporting that measurement of miRNAs may also represent potential biomarkers for cancer detection [121, 122]. In addition, plasma metabolomics studies have shown distinct glucose metabolism profiles during progression from chronic atrophic gastritis to intestinal metaplasia, gastric dysplasia and ultimately to gastric cancer [123]. Similar unique metabolic patterns have been identified in lung cancer [124] and oral squamous cell carcinoma pathways [125] as well. By incorporating a more integrative approach, Bro and colleagues recent created Biocontour [126], a novel risk assessment scale that combines metabolic profile analysis of plasma samples and relevant lifestyle information to predict cancer risk. With a sensitivity and specificity superior to traditional screening mammography, Biocontour was shown to predict individual diagnoses of breast cancer several years ahead of diagnosis [126]. If these applications are validated in larger populations, future studies may be able to implement these tools to predict the effect of interventions on cancer development and help identify those individuals with high-risk that should be enrolled in cancer prevention trials.

A fundamental challenge that still remains in dietary phytochemical research is the lack of consensus regarding the optimal dose of many of these compounds to be used in trials. High doses of synthetic bioactive agents have been commonly administered based frequently on data obtained in pre-clinical studies, and likely represent unrealistic and non-physiological conditions. It is conceivable, though, that phytochemicals exert their optimal anti-cancer activity at dietary relevant doses. Cai and colleagues compared the target-tissue distribution and activity of low dietary doses $(5 \mathrm{mg}$ ) with an intake 200 fold higher, and found that low dietary dose not only elicit biological changes in mouse and human colonic tissues, but also have superior efficacy compared to higher doses [127]. In this study, low concentrations of resveratrol prevented colonic tumor progression in mice and correlated with the induction of AMPK and senescence, and these effects were also notably reproduced in human tissue. These results may indicate that other diet-derived agents may exert cancer chemopreventive qualities at low dietary doses as well.

\section{CONCLUDING REMARKS}

Over the last two decades, there have been several studies that have clearly shown that dietary agents have anti-cancer properties and epidemiological studies have corroborated that cancer prevalence varies based upon several factors including dietary consumptions. Despite encouraging in-vitro data, randomized clinical trials aimed at exposing these effects have been extremely difficult to characterize. To improve upon the ability to identify these effects, many studies have identified predictors including biomarkers and other surrogate markers such as high risk pre-cancerous lesions to serve as additional predictors to identify regression and progression as markers of change. Understanding how these dietary agents interact with cancer cells, the immune system and oxidative stress pathways may uncover safe, non-toxic and economical anti-cancer therapeutics in the future.

\section{CONFLICT OF INTEREST}

There is no conflict of interest to declare.

\section{GRANT SUPPORT}

AT was supported in part by grants from the Ministry of Education, Culture, Sports and Technology of Japan, a Research on Allergic Disease and Immunology (H26106) in Health and Labor Science Grant from the Ministry of Health, Labour and Welfare of Japan, the SENSHIN 
Medical Research Foundation (Osaka, Japan), the Aichi Cancer Research Foundation (Nagoya, Japan), and the 24th General Assembly of the Japanese Association of Medical Sciences (Nagoya, Japan). The funders played no role in the study design, data collection and analysis, the decision to publish or the preparation of the manuscript.

\section{REFERENCES}

1. Torre LA, Bray F, Siegel RL, Ferlay J, Lortet-Tieulent J, Jemal A. Global cancer statistics, 2012. CA Cancer J Clin. 2015; 65:87-108.

2. Aleksandrova K, Pischon T, Jenab M, Bueno-de-Mesquita HB, Fedirko V, Norat T, Romaguera D, Knüppel S, Boutron-Ruault MC, Dossus L, Dartois L, Kaaks R, Li $\mathrm{K}$, et al. Combined impact of healthy lifestyle factors on colorectal cancer: a large European cohort study. BMC Med. 2014; 12:168.

3. Garcia DO, Thomson CA. Physical activity and cancer survivorship. Nutr Clin Pract. 2014; 29:768-79.

4. Mehta M, Shike M. Diet and physical activity in the prevention of colorectal cancer. J Natl Compr Canc Netw. 2014; 12:1721-6.

5. Howes MJ, Simmonds MS. The role of phytochemicals as micronutrients in health and disease. Curr Opin Clin Nutr Metab Care. 2014; 17:558-66.

6. Murakami A. Chemoprevention with phytochemicals targeting inducible nitric oxide synthase. Forum Nutr. 2009; 61:193-203

7. Priyadarsini RV, Nagini S. Cancer chemoprevention by dietary phytochemicals: promises and pitfalls. Curr Pharm Biotechnol. 2012; 13:125-36.

8. Surh YJ. Cancer chemoprevention with dietary phytochemicals. Nat Rev Cancer. 2003; 3:768-80.

9. Lee KW, Bode AM, Dong Z. Molecular targets of phytochemicals for cancer prevention. Nat Rev Cancer. 2011; 11:211-8.

10. Loeb LA, Harris CC. Advances in chemical carcinogenesis: a historical review and prospective. Cancer Res. 2008; 68:6863-72.

11. Tokarz P, Blasiak J. Role of mitochondria in carcinogenesis. Acta Biochim Pol. 2014; 61:671-8.

12. Barcellos-Hoff MH, Lyden D, Wang TC. The evolution of the cancer niche during multistage carcinogenesis. Nat Rev Cancer. 2013; 13:511-8.

13. Ashkenazi R, Gentry SN, Jackson TL. Pathways to tumorigenesis--modeling mutation acquisition in stem cells and their progeny. Neoplasia. 2008; 10:1170-82.

14. Quail DF, Joyce JA. Microenvironmental regulation of tumor progression and metastasis. Nat Med. 2013; 19:142337.

15. Kim R, Emi M, Tanabe K. Cancer immunoediting from immune surveillance to immune escape. Immunology.
2007; 121:1-14.

16. Aoi J, Endo M, Kadomatsu T, Miyata K, Ogata A, Horiguchi H, Odagiri H, Masuda T, Fukushima S, Jinnin M, Hirakawa S, Sawa T, Akaike T, Ihn H, Oike Y. Angiopoietin-like protein 2 accelerates carcinogenesis by activating chronic inflammation and oxidative stress. Mol Cancer Res. 2014; 12:239-49.

17. Letelier P, Brebi P, Tapia O, Roa JC. DNA promoter methylation as a diagnostic and therapeutic biomarker in gallbladder cancer. Clin Epigenetics. 2012; 4:11.

18. Suzuki HI, Katsura A, Matsuyama H, Miyazono K. MicroRNA regulons in tumor microenvironment. Oncogene. 2015; 34:3085-94.

19. Sapienza C, Issa JP. Diet, Nutrition, and Cancer Epigenetics. Annu Rev Nutr. 2016.

20. Collins AR, Azqueta A, Langie SA. Effects of micronutrients on DNA repair. Eur J Nutr. 2012; 51:261-79.

21. Royston KJ, Tollefsbol TO. The Epigenetic Impact of Cruciferous Vegetables on Cancer Prevention. Curr Pharmacol Rep. 2015; 1:46-51.

22. Luis Espinoza J, Takami A, Trung LQ, Nakao S. Ataxiatelangiectasia mutated kinase-mediated upregulation of NKG2D ligands on leukemia cells by resveratrol results in enhanced natural killer cell susceptibility. Cancer Sci. 2013; 104:657-62.

23. Shehzad A, Wahid F, Lee YS. Curcumin in cancer chemoprevention: molecular targets, pharmacokinetics, bioavailability, and clinical trials. Arch Pharm (Weinheim). 2010; 343:489-99.

24. Bar-Sela G, Epelbaum R, Schaffer M. Curcumin as an anticancer agent: review of the gap between basic and clinical applications. Curr Med Chem. 2010; 17:190-7.

25. Hasima N, Aggarwal BB. Targeting proteasomal pathways by dietary curcumin for cancer prevention and treatment. Curr Med Chem. 2014; 21:1583-94.

26. Bortel N, Armeanu-Ebinger S, Schmid E, Kirchner B, Frank J, Kocher A, Schiborr C, Warmann S, Fuchs J, Ellerkamp V. Effects of curcumin in pediatric epithelial liver tumors: inhibition of tumor growth and alpha-fetoprotein in vitro and in vivo involving the NFkappaB- and the beta-catenin pathways. Oncotarget. 2015; 6:40680-91. doi: 10.18632/ oncotarget.5673.

27. Yang C, Su X, Liu A, Zhang L, Yu A, Xi Y, Zhai G. Advances in clinical study of curcumin. Curr Pharm Des. 2013; 19:1966-73.

28. Dhillon N, Aggarwal BB, Newman RA, Wolff RA, Kunnumakkara AB, Abbruzzese JL, Ng CS, Badmaev V, Kurzrock R. Phase II trial of curcumin in patients with advanced pancreatic cancer. Clin Cancer Res. 2008; $14: 4491-9$.

29. Epelbaum R, Schaffer M, Vizel B, Badmaev V, Bar-Sela G. Curcumin and gemcitabine in patients with advanced pancreatic cancer. Nutr Cancer. 2010; 62:1137-41. 
30. Sharma RA, McLelland HR, Hill KA, Ireson CR, Euden SA, Manson MM, Pirmohamed M, Marnett LJ, Gescher AJ, Steward WP. Pharmacodynamic and pharmacokinetic study of oral Curcuma extract in patients with colorectal cancer. Clin Cancer Res. 2001; 7:1894-900.

31. Cruz-Correa M, Shoskes DA, Sanchez P, Zhao R, Hylind LM, Wexner SD, Giardiello FM. Combination treatment with curcumin and quercetin of adenomas in familial adenomatous polyposis. Clin Gastroenterol Hepatol. 2006; 4:1035-8.

32. Carroll RE, Benya RV, Turgeon DK, Vareed S, Neuman M, Rodriguez L, Kakarala M, Carpenter PM, McLaren C, Meyskens FL, Brenner DE. Phase IIa clinical trial of curcumin for the prevention of colorectal neoplasia. Cancer Prev Res (Phila). 2011; 4:354-64.

33. Cheng AL, Hsu CH, Lin JK, Hsu MM, Ho YF, Shen TS, Ko JY, Lin JT, Lin BR, Ming-Shiang W, Yu HS, Jee SH, et al. Phase I clinical trial of curcumin, a chemopreventive agent, in patients with high-risk or pre-malignant lesions. Anticancer Res. 2001; 21:2895-900.

34. Shoba G, Joy D, Joseph T, Majeed M, Rajendran R, Srinivas PS. Influence of piperine on the pharmacokinetics of curcumin in animals and human volunteers. Planta Med. 1998; 64:353-6.

35. Prasad S, Tyagi AK, Aggarwal BB. Recent developments in delivery, bioavailability, absorption and metabolism of curcumin: the golden pigment from golden spice. Cancer Res Treat. 2014; 46:2-18.

36. Huang Q, Yu H, Ru Q. Bioavailability and delivery of nutraceuticals using nanotechnology. J Food Sci. 2010; 75:R50-7.

37. Storka A, Vcelar B, Klickovic U, Gouya G, Weisshaar S, Aschauer S, Bolger G, Helson L, Wolzt M. Safety, tolerability and pharmacokinetics of liposomal curcumin in healthy humans. Int J Clin Pharmacol Ther. 2015; 53:54-65.

38. Schiborr C, Kocher A, Behnam D, Jandasek J, Toelstede $\mathrm{S}$, Frank J. The oral bioavailability of curcumin from micronized powder and liquid micelles is significantly increased in healthy humans and differs between sexes. Mol Nutr Food Res. 2014; 58:516-27.

39. Keylor MH, Matsuura BS, Stephenson CR. Chemistry and Biology of Resveratrol-Derived Natural Products. Chem Rev. 2015; 115:8976-9027.

40. Espinoza JL, Takami A, Trung LQ, Kato S, Nakao S. Resveratrol Prevents EBV Transformation and Inhibits the Outgrowth of EBV-Immortalized Human B Cells. PLoS One. 2012; 7:e51306.

41. Scott E, Steward WP, Gescher AJ, Brown K. Resveratrol in human cancer chemoprevention--choosing the 'right' dose. Mol Nutr Food Res. 2012; 56:7-13.

42. Shukla Y, Singh R. Resveratrol and cellular mechanisms of cancer prevention. Ann N Y Acad Sci. 2011; 1215:1-8.

43. Quoc Trung L, Espinoza JL, Takami A, Nakao S.
Resveratrol Induces Cell Cycle Arrest and Apoptosis in Malignant NK Cells via JAK2/STAT3 Pathway Inhibition. PLoS One. 2013; 8:e55183.

44. Trung LQ, Espinoza JL, An DT, Viet NH, Shimoda K, Nakao S. Resveratrol selectively induces apoptosis in malignant cells with the JAK2V617F mutation by inhibiting the JAK2 pathway. Mol Nutr Food Res. 2015; 59:2143-54. doi: 10.1002/mnfr.201500166.

45. Kato A, Naiki-Ito A, Nakazawa T, Hayashi K, Naitoh I, Miyabe K, Shimizu S, Kondo H, Nishi Y, Yoshida M, Umemura S, Hori Y, et al. Chemopreventive effect of resveratrol and apocynin on pancreatic carcinogenesis via modulation of nuclear phosphorylated GSK3 $\beta$ and ERK1/2. Oncotarget. 2015; 6:42963-75. doi: 10.18632/ oncotarget.5981.

46. Patel KR, Scott E, Brown VA, Gescher AJ, Steward WP, Brown K. Clinical trials of resveratrol. Ann N Y Acad Sci. 2011; 1215:161-9.

47. Brown VA, Patel KR, Viskaduraki M, Crowell JA, Perloff M, Booth TD, Vasilinin G, Sen A, Schinas AM, Piccirilli G, Brown K, Steward WP, Gescher AJ, Brenner DE. Repeat dose study of the cancer chemopreventive agent resveratrol in healthy volunteers: safety, pharmacokinetics, and effect on the insulin-like growth factor axis. Cancer Res. 2010; 70:9003-11.

48. Renehan AG, Zwahlen M, Minder C, O'Dwyer ST, Shalet SM, Egger M. Insulin-like growth factor (IGF)-I, IGF binding protein-3, and cancer risk: systematic review and meta-regression analysis. Lancet. 2004; 363:1346-53.

49. Tran CD, Diorio C, Bérubé S, Pollak M, Brisson J. Relation of insulin-like growth factor (IGF) I and IGF-binding protein 3 concentrations with intakes of fruit, vegetables, and antioxidants. Am J Clin Nutr. 2006; 84:1518-26.

50. Chow HH, Garland LL, Hsu CH, Vining DR, Chew WM, Miller JA, Perloff M, Crowell JA, Alberts DS. Resveratrol modulates drug- and carcinogen-metabolizing enzymes in a healthy volunteer study. Cancer Prev Res (Phila). 2010; 3:1168-75.

51. Levi F, Pasche C, Lucchini F, Ghidoni R, Ferraroni M, La Vecchia C. Resveratrol and breast cancer risk. Eur J Cancer Prev. 2005; 14:139-42.

52. Zhu W, Qin W, Zhang K, Rottinghaus GE, Chen YC, Kliethermes B, Sauter ER. Trans-resveratrol alters mammary promoter hypermethylation in women at increased risk for breast cancer. Nutr Cancer. 2012; 64:393400.

53. Kjaer TN, Ornstrup MJ, Poulsen MM, Jørgensen JO, Hougaard DM, Cohen AS, Neghabat S, Richelsen B, Pedersen SB. Resveratrol reduces the levels of circulating androgen precursors but has no effect on, testosterone, dihydrotestosterone, PSA levels or prostate volume. A 4-month randomised trial in middle-aged men. Prostate. 2015; 75:1255-63. 
54. Seeni A, Takahashi S, Takeshita K, Tang M, Sugiura S, Sato SY, Shirai T. Suppression of prostate cancer growth by resveratrol in the transgenic rat for adenocarcinoma of prostate (TRAP) model. Asian Pac J Cancer Prev. 2008; 9:7-14.

55. Bui JD, Schreiber RD. Cancer immunosurveillance, immunoediting and inflammation: independent or interdependent processes? Curr Opin Immunol. 2007; 19:203-8.

56. Guerra N, Tan Y, Joncker N, Choy A, Gallardo F, Xiong N, Knoblaugh S, Cado D, Greenberg N, Greenberg N, Raulet D. NKG2D-deficient mice are defective in tumor surveillance in models of spontaneous malignancy. Immunity. 2008; 28:571-80.

57. Espinoza LJ AD, Trung LQ, Yamada K, Nakao S, et al. Stilbene derivatives from melinjo extract have antioxidant and immune modulatory effects in healthy individuals. Integr Mol Med; . 2015.

58. Neves AR, Lucio M, Lima JL, Reis S. Resveratrol in medicinal chemistry: a critical review of its pharmacokinetics, drug-delivery, and membrane interactions. Curr Med Chem. 2012; 19:1663-81.

59. Johnson JJ, Nihal M, Siddiqui IA, Scarlett CO, Bailey HH, Mukhtar H, Ahmad N. Enhancing the bioavailability of resveratrol by combining it with piperine. Mol Nutr Food Res. 2011; 55:1169-76.

60. Smoliga JM, Blanchard O. Enhancing the delivery of resveratrol in humans: if low bioavailability is the problem, what is the solution? Molecules. 2014; 19:17154-72.

61. Sanna V, Siddiqui IA, Sechi M, Mukhtar H. Resveratrolloaded nanoparticles based on poly(epsilon-caprolactone) and poly(D,L-lactic-co-glycolic acid)-poly(ethylene glycol) blend for prostate cancer treatment. Mol Pharm. 2013; 10:3871-81

62. Figueiró F, Bernardi A, Frozza RL, Terroso T, ZanottoFilho A, Jandrey EH, Moreira JC, Salbego CG, Edelweiss MI, Pohlmann AR, Guterres SS, Battastini AM. Resveratrol-loaded lipid-core nanocapsules treatment reduces in vitro and in vivo glioma growth. J Biomed Nanotechnol. 2013; 9:516-26.

63. Chang CW, Wong CY, Wu YT, Hsu MC. Development of a Solid Dispersion System for Improving the Oral Bioavailability of Resveratrol in Rats. Eur J Drug Metab Pharmacokinet. 2016.

64. Balata GF, Essa EA, Shamardl HA, Zaidan SH, Abourehab MA. Self-emulsifying drug delivery systems as a tool to improve solubility and bioavailability of resveratrol. Drug Des Devel Ther. 2016; 10:117-28.

65. Seeram NP, Henning SM, Niu Y, Lee R, Scheuller HS, Heber D. Catechin and caffeine content of green tea dietary supplements and correlation with antioxidant capacity. J Agric Food Chem. 2006; 54:1599-603.

66. $\mathrm{Wu} \mathrm{AH}, \mathrm{Yu} \mathrm{MC}$. Tea, hormone-related cancers and endogenous hormone levels. Mol Nutr Food Res. 2006; 50:160-9.

67. Yiannakopoulou ECh. Effect of green tea catechins on breast carcinogenesis: a systematic review of in-vitro and in-vivo experimental studies. Eur J Cancer Prev. 2014; 23:84-9.

68. Steele VE, Kelloff GJ, Balentine D, Boone CW, Mehta R, Bagheri D, Sigman CC, Zhu S, Sharma S. Comparative chemopreventive mechanisms of green tea, black tea and selected polyphenol extracts measured by in vitro bioassays. Carcinogenesis. 2000; 21:63-7.

69. Sun CL, Yuan JM, Koh WP, Yu MC. Green tea, black tea and breast cancer risk: a meta-analysis of epidemiological studies. Carcinogenesis. 2006; 27:1310-5.

70. Wu Y, Zhang D, Kang S. Black tea, green tea and risk of breast cancer: an update. Springerplus. 2013; 2:240.

71. Li N, Sun Z, Han C, Chen J. The chemopreventive effects of tea on human oral precancerous mucosa lesions. Proc Soc Exp Biol Med. 1999; 220:218-24.

72. Valavanidis A, Vlachogianni T, Fiotakis C. 8-hydroxy-2' -deoxyguanosine (8-OHdG): A critical biomarker of oxidative stress and carcinogenesis. J Environ Sci Health C Environ Carcinog Ecotoxicol Rev. 2009; 27:120-39.

73. Hakim IA, Harris RB, Brown S, Chow HH, Wiseman S, Agarwal S, Talbot W. Effect of increased tea consumption on oxidative DNA damage among smokers: a randomized controlled study. J Nutr. 2003; 133:3303S-09S.

74. Hakim IA, Chow HH, Harris RB. Green tea consumption is associated with decreased DNA damage among GSTM1positive smokers regardless of their hOGG1 genotype. J Nutr. 2008; 138:1567S-71S.

75. Luo H, Tang L, Tang M, Billam M, Huang T, Yu J, Wei Z, Liang Y, Wang K, Zhang ZQ, Zhang L, Wang JS. Phase IIa chemoprevention trial of green tea polyphenols in high-risk individuals of liver cancer: modulation of urinary excretion of green tea polyphenols and 8-hydroxydeoxyguanosine. Carcinogenesis. 2006; 27:262-8.

76. Hamajima N, Tajima $\mathrm{K}$, Tominaga S, Matsuura A, Kuwabara M, Okuma K. Tea polyphenol intake and changes in serum pepsinogen levels. Jpn J Cancer Res. 1999; 90:136-43.

77. Sosa V, Moliné T, Somoza R, Paciucci R, Kondoh H, LLeonart ME. Oxidative stress and cancer: an overview. Ageing Res Rev. 2013; 12:376-90.

78. Tong L, Chuang CC, Wu S, Zuo L. Reactive oxygen species in redox cancer therapy. Cancer Lett. 2015; 367:18-25.

79. Glasauer A, Chandel NS. Targeting antioxidants for cancer therapy. Biochem Pharmacol. 2014; 92:90-101.

80. Greenwald P, Anderson D, Nelson SA, Taylor PR. Clinical trials of vitamin and mineral supplements for cancer prevention. Am J Clin Nutr. 2007; 85:314S-17S.

81. Albanes D, Heinonen OP, Taylor PR, Virtamo J, Edwards BK, Rautalahti M, Hartman AM, Palmgren J, Freedman 
LS, Haapakoski J, Barrett MJ, Pietinen P, Malila N, Tala E, Liippo K, Salomaa ER, Tangrea JA, Teppo L, Askin FB, Taskinen E, Erozan Y, Greenwald P, Huttunen JK. AlphaTocopherol and beta-carotene supplements and lung cancer incidence in the alpha-tocopherol, beta-carotene cancer prevention study: effects of base-line characteristics and study compliance. J Natl Cancer Inst. 1996; 88:1560-70.

82. Goodman GE, Thornquist MD, Balmes J, Cullen MR, Meyskens FL, Omenn GS, Valanis B, Williams JH. The Beta-Carotene and Retinol Efficacy Trial: incidence of lung cancer and cardiovascular disease mortality during 6-year follow-up after stopping beta-carotene and retinol supplements. J Natl Cancer Inst. 2004; 96:1743-50.

83. Blot WJ, Li JY, Taylor PR, Guo W, Dawsey S, Wang GQ, Yang CS, Zheng SF, Gail M, Li GY. Nutrition intervention trials in Linxian, China: supplementation with specific vitamin/mineral combinations, cancer incidence, and disease-specific mortality in the general population. J Natl Cancer Inst. 1993; 85:1483-92.

84. Qiao YL, Dawsey SM, Kamangar F, Fan JH, Abnet CC, Sun XD, Johnson LL, Gail MH, Dong ZW, Yu B, Mark SD, Taylor PR. Total and cancer mortality after supplementation with vitamins and minerals: follow-up of the Linxian General Population Nutrition Intervention Trial. J Natl Cancer Inst. 2009; 101:507-18.

85. The effect of vitamin $\mathrm{E}$ and beta carotene on the incidence of lung cancer and other cancers in male smokers. The Alpha-Tocopherol, Beta Carotene Cancer Prevention Study Group. N Engl J Med. 1994; 330:1029-35.

86. Virtamo J, Edwards BK, Virtanen M, Taylor PR, Malila N, Albanes D, Huttunen JK, Hartman AM, Hietanen P, Mäenpää H, Koss L, Nordling S, Heinonen OP. Effects of supplemental alpha-tocopherol and beta-carotene on urinary tract cancer: incidence and mortality in a controlled trial (Finland). Cancer Causes Control. 2000; 11:933-9.

87. Rautalahti MT, Virtamo JR, Taylor PR, Heinonen OP, Albanes D, Haukka JK, Edwards BK, Kärkkäinen PA, Stolzenberg-Solomon RZ, Huttunen J. The effects of supplementation with alpha-tocopherol and beta-carotene on the incidence and mortality of carcinoma of the pancreas in a randomized, controlled trial. Cancer. 1999; 86:37-42.

88. Wright ME, Virtamo J, Hartman AM, Pietinen P, Edwards BK, Taylor PR, Huttunen JK, Albanes D. Effects of alphatocopherol and beta-carotene supplementation on upper aerodigestive tract cancers in a large, randomized controlled trial. Cancer. 2007; 109:891-8.

89. Gaziano JM, Glynn RJ, Christen WG, Kurth T, Belanger C, MacFadyen J, Bubes V, Manson JE, Sesso HD, Buring JE. Vitamins $\mathrm{E}$ and $\mathrm{C}$ in the prevention of prostate and total cancer in men: the Physicians' Health Study II randomized controlled trial. JAMA. 2009; 301:52-62.

90. Wang L, Sesso HD, Glynn RJ, Christen WG, Bubes V, Manson JE, Buring JE, Gaziano JM. Vitamin E and C supplementation and risk of cancer in men: posttrial followup in the Physicians' Health Study II randomized trial. Am
J Clin Nutr. 2014; 100:915-23.

91. Hercberg S, Galan P, Preziosi P, Bertrais S, Mennen L, Malvy D, Roussel AM, Favier A, Briançon S. The SU.VI. MAX Study: a randomized, placebo-controlled trial of the health effects of antioxidant vitamins and minerals. Arch Intern Med. 2004; 164:2335-42.

92. Hercberg S, Kesse-Guyot E, Druesne-Pecollo N, Touvier M, Favier A, Latino-Martel P, Briançon S, Galan P. Incidence of cancers, ischemic cardiovascular diseases and mortality during 5-year follow-up after stopping antioxidant vitamins and minerals supplements: a postintervention follow-up in the SU.VI.MAX Study. Int J Cancer. 2010; 127:1875-81.

93. Ezzedine K, Latreille J, Kesse-Guyot E, Galan P, Hercberg $\mathrm{S}$, Guinot C, Malvy D. Incidence of skin cancers during 5-year follow-up after stopping antioxidant vitamins and mineral supplementation. Eur J Cancer. 2010; 46:3316-22.

94. Klein EA, Thompson IM, Tangen CM, Crowley JJ, Lucia MS, Goodman PJ, Minasian LM, Ford LG, Parnes HL, Gaziano JM, Karp DD, Lieber MM, Walther PJ, et al. Vitamin E and the risk of prostate cancer: the Selenium and Vitamin E Cancer Prevention Trial (SELECT). JAMA. 2011; 306:1549-56.

95. Lippman SM, Klein EA, Goodman PJ, Lucia MS, Thompson IM, Ford LG, Parnes HL, Minasian LM, Gaziano JM, Hartline JA, Parsons JK, Bearden JD, Crawford ED, et al. Effect of selenium and vitamin $\mathrm{E}$ on risk of prostate cancer and other cancers: the Selenium and Vitamin E Cancer Prevention Trial (SELECT). JAMA. 2009; 301:3951.

96. Kristal AR, Darke AK, Morris JS, Tangen CM, Goodman PJ, Thompson IM, Meyskens FL, Goodman GE, Minasian LM, Parnes HL, Lippman SM, Klein EA. Baseline selenium status and effects of selenium and vitamin e supplementation on prostate cancer risk. J Natl Cancer Inst. 2014; 106:djt456.

97. Vance TM, Su J, Fontham ET, Koo SI, Chun OK. Dietary antioxidants and prostate cancer: a review. Nutr Cancer. 2013; 65:793-801.

98. Bailey LB, Gregory JF. Folate metabolism and requirements. J Nutr. 1999; 129:779-82.

99. Dary O. Nutritional interpretation of folic acid interventions. Nutr Rev. 2009; 67:235-44.

100. Lamprecht SA, Lipkin M. Chemoprevention of colon cancer by calcium, vitamin D and folate: molecular mechanisms. Nat Rev Cancer. 2003; 3:601-14.

101. Tio M, Andrici J, Cox MR, Eslick GD. Folate intake and the risk of upper gastrointestinal cancers: a systematic review and meta-analysis. J Gastroenterol Hepatol. 2014; 29:250-8.

102. Chen P, Li C, Li X, Li J, Chu R, Wang H. Higher dietary folate intake reduces the breast cancer risk: a systematic review and meta-analysis. Br J Cancer. 2014; 110:2327-38.

103. Jaszewski R, Misra S, Tobi M, Ullah N, Naumoff JA, Kucuk O, Levi E, Axelrod BN, Patel BB, Majumdar AP. Folic acid supplementation inhibits recurrence of colorectal 
adenomas: a randomized chemoprevention trial. World $\mathrm{J}$ Gastroenterol. 2008; 14:4492-8.

104. Figueiredo JC, Mott LA, Giovannucci E, Wu K, Cole B, Grainge MJ, Logan RF, Baron JA. Folic acid and prevention of colorectal adenomas: a combined analysis of randomized clinical trials. Int J Cancer. 2011; 129:192-203.

105. Carroll C, Cooper K, Papaioannou D, Hind D, Tappenden P, Pilgrim H, Booth A. Meta-analysis: folic acid in the chemoprevention of colorectal adenomas and colorectal cancer. Aliment Pharmacol Ther. 2010; 31:708-18.

106. Cole BF, Baron JA, Sandler RS, Haile RW, Ahnen DJ, Bresalier RS, McKeown-Eyssen G, Summers RW, Rothstein RI, Burke CA, Snover DC, Church TR, Allen JI, Robertson DJ, Beck GJ, Bond JH, Byers T, Mandel JS, Mott LA, Pearson LH, Barry EL, Rees JR, Marcon N, Saibil F, Ueland PM, Greenberg ER, Group PPS. Folic acid for the prevention of colorectal adenomas: a randomized clinical trial. JAMA. 2007; 297:2351-9.

107. Wien TN, Pike E, Wisløff T, Staff A, Smeland S, Klemp M. Cancer risk with folic acid supplements: a systematic review and meta-analysis. BMJ Open. 2012; 2:e000653.

108. Shi J, Le Maguer M. Lycopene in tomatoes: chemical and physical properties affected by food processing. Crit Rev Biotechnol. 2000; 20:293-334.

109. Palozza P, Parrone N, Catalano A, Simone R. Tomato lycopene and inflammatory cascade: basic interactions and clinical implications. Curr Med Chem. 2010; 17:2547-63.

110. Ono M, Takeshima M, Nakano S. Mechanism of the Anticancer Effect of Lycopene (Tetraterpenoids). Enzymes. 2015; 37:139-66.

111. Key TJ, Appleby PN, Travis RC, Albanes D, Alberg AJ, Barricarte A, Black A, Boeing H, Bueno-de-Mesquita HB, Chan JM, Chen C, Cook MB, et al. Carotenoids, retinol, tocopherols, and prostate cancer risk: pooled analysis of 15 studies. Am J Clin Nutr. 2015; 102:1142-57.

112. Chen J, Song Y, Zhang L. Lycopene/tomato consumption and the risk of prostate cancer: a systematic review and meta-analysis of prospective studies. J Nutr Sci Vitaminol (Tokyo). 2013; 59:213-23.

113. Ilic D, Forbes KM, Hassed C. Lycopene for the prevention of prostate cancer. Cochrane Database Syst Rev. 2011:CD008007.

114. Etminan M, Takkouche B, Caamaño-Isorna F. The role of tomato products and lycopene in the prevention of prostate cancer: a meta-analysis of observational studies. Cancer Epidemiol Biomarkers Prev. 2004; 13:340-5.

115. Gontero P, Marra G, Soria F, Oderda M, Zitella A, Baratta F, Chiorino G, Gregnanin I, Daniele L, Cattel L, Frea B, Brusa P. A randomized double-blind placebo controlled phase I-II study on clinical and molecular effects of dietary supplements in men with precancerous prostatic lesions. Chemoprevention or "chemopromotion"? Prostate. 2015; 75:1177-86.
116. Landis-Piwowar KR, Iyer NR. Cancer chemoprevention: current state of the art. Cancer Growth Metastasis. 2014; 7:19-25.

117. Steward WP, Brown K. Cancer chemoprevention: a rapidly evolving field. Br J Cancer. 2013; 109:1-7.

118. William WN, Papadimitrakopoulou VA. Optimizing biomarkers and endpoints in oral cancer chemoprevention trials. Cancer Prev Res (Phila). 2013; 6:375-8.

119. Prentice RL. Surrogate endpoints in clinical trials: definition and operational criteria. Stat Med. 1989; 8:431-40.

120. Gustafson AM, Soldi R, Anderlind C, Scholand MB, Qian J, Zhang X, Cooper K, Walker D, McWilliams A, Liu G, Szabo E, Brody J, Massion PP, Lenburg ME, Lam S, Bild AH, Spira A. Airway PI3K pathway activation is an early and reversible event in lung cancer development. Sci Transl Med. 2010; 2:26ra25.

121. Hu L, Ai J, Long H, Liu W, Wang X, Zuo Y, Li Y, Wu Q, Deng Y. Integrative microRNA and gene profiling data analysis reveals novel biomarkers and mechanisms for lung cancer. Oncotarget. 2016; 7:8441-54. doi: 10.18632/ oncotarget. 7264 .

122. Hannafon BN, Sebastiani P, de las Morenas A, Lu J, Rosenberg CL. Expression of microRNA and their gene targets are dysregulated in preinvasive breast cancer. Breast Cancer Res. 2011; 13:R24.

123. Yuan LW, Yamashita H, Seto Y. Glucose metabolism in gastric cancer: The cutting-edge. World J Gastroenterol. 2016; 22:2046-59.

124. Puchades-Carrasco L, Jantus-Lewintre E, Pérez-Rambla C, García-García F, Lucas R, Calabuig S, Blasco A, Dopazo J, Camps C, Pineda-Lucena A. Serum metabolomic profiling facilitates the non-invasive identification of metabolic biomarkers associated with the onset and progression of non-small cell lung cancer. Oncotarget. 2016; 7:12904-16. doi: 10.18632/oncotarget.7354.

125. Grimm M, Hoefert S, Krimmel M, Biegner T, Feyen $\mathrm{O}$, Teriete $\mathrm{P}$, Reinert S. Monitoring carcinogenesis in a case of oral squamous cell carcinoma using a panel of new metabolic blood biomarkers as liquid biopsies. Oral Maxillofac Surg. 2016.

126. Bro R, Kamstrup-Nielsen MH, Engelsen SB, Savorani F, Rasmussen MA, Hansen L, Olsen A, Tjønneland A, Dragsted LO. Forecasting individual breast cancer risk using plasma metabolomics and biocontours. Metabolomics. 2015; 11:1376-80.

127. Cai H, Scott E, Kholghi A, Andreadi C, Rufini A, Karmokar A, Britton RG, Horner-Glister E, Greaves P, Jawad D, James M, Howells L, Ognibene T, Malfatti M, Goldring C, Kitteringham N, Walsh J, Viskaduraki M, West K, Miller A, Hemingway D, Steward WP, Gescher AJ, Brown K. Cancer chemoprevention: Evidence of a nonlinear dose response for the protective effects of resveratrol in humans and mice. Sci Transl Med. 2015; 7:298ra117. 